\title{
Artificial Intelligence in China, Recent Trends
}

\#1 Department of Electronics and Communication Engineering, Institute of Technology, University of Kashmir, Srinagar, Jammu and Kashmir, India, +91-9797138844,

\#2 Department of Electronics and Communication Engineering, Institute of Technology, University of Kashmir, Srinagar, Jammu and Kashmir, India

\section{ABSTRACT}

Artificial Intelligence (AI) is playing a key role in harboring and promoting the enormous potential of the computing resources encompassing- the artificial, viz. hardware and software, as well as the human, viz. the research community and the human workforce available. A shift of power centers for the AI community from the United States to China, is evident with the decision of Google Inc., the technology giant, to start an AI center in Beijing, China. This comes at the heels of Chinese government's landmark announcement earlier in 2017 that it has plans to build a 1 trillion-yuan ( $\$ 147.9$ billion) AI centered industry by 2030 , which is going to touch almost 10 trillion yuan in businesses which are related to AI. China is aiming to become a global leader in the Research and Development of AI, coupled with AI's application to healthcare, manufacturing and financial market areas

Key words: Autonomous vehicles, Medical robotics, Big data, Artificial Intelligence, Recent trends in Artificial Intelligence.

Corresponding Author: Abdul Mueed Hafiz

\section{INTRODUCTION: A SHIFT OF POWER CENTERS}

Google, the global giant in technology proclaimed recently starting of its Artificial Intelligence (AI) center in China in its Shanghai second developers conference [1].

The upcoming AI center is going to be based in national capital, Beijing. A limited number of researchers backed up by hundreds of Chinese expert engineers are going to be operating in the center. Basic Artificial Intelligence study and development is going to be the focus of the new center. Li Feifei, principal scientist of AI and pattern recognition at Google Cloud, is going to be the lead the research in the AI center. She said that the center is going to be an effort on the level of corporates. She also said that it will be one among the primary steps for Google to hold out long-run analysis within the Chinese market. The center's preparation begun in January. A variety of Google's research groups, like that of Tensor Flow - computation with the help of knowledge-flowing graphs or vectors, for the purpose of machine learning, will be taking part in starting of new center. 
DOI: https://dx.doi.org/10.26808/rs.ca.i8v2.09

International Journal of Computer Application (2250-1797)

Issue 8 Volume 2, March-April 2018

\section{REASON FOR THE SHIFT: KEY AI GUIDELINES RECENTLY UNVEILED BY CHINA}

China recently dropped the veil on a 3-year plan to boost applications of AI in the automobile industry, robotics, healthcare sector and other key areas, as part of its recent effort to upgrade its actual economy [2].

This strategy, notified officially on the website of the Chinese Ministry of Industry and IT, reported that China now aims to develop a smart e-connected automobile industry by the year 2020 in face of global competition, with the inclusion of breakthroughs in the auto-driving vehicle platform.

Also, Artificial Intelligence-based service robots are going to be available widely in the country within a span of 3 years. These robots will be focused on helping children as well as senior citizens. The plan also unveiled the aim to enhance the use of AI to help doctors in dealing with diagnosis, etc. in medical cases.

The important Chinese decision reports on the aims to enhance AI into other industrial sectors by 2025. China announced earlier in 2017 that it has plans to build a 1 trillion-yuan (\$147.9 billion) AI centered industry by 2030 , which is going to touch almost 10 trillion yuan in businesses which are related to AI.

China is aiming to become a global leader in the R\&D of AI, coupled with AI's application to healthcare, manufacturing and financial market areas. During November 2017, the China said it was going to develop 4 national AI innovational platforms with the help of Alibaba Group for smart city based technology, Baidu Inc for auto-drive technology, Tencent Holdings Ltd for AIassisted medical diagnosis and treatment, and iFlytek Co Ltd in AI-based speech-recognition technology.

The president for the Academy of Engineering at China, Zhou Ji, also said that AI-related technologies are playing a key role in recent technologies' revolution and had direct effect on transforming the industry, e.g. smart manufacturing.

Local governments like Zhongguancun, a hub of technology in Beijing, are rushing in for the opportunity by stating their aim to host five hundred AI companies by the year 2020, besides 5 of these companies to be competitive on a global level. This dynamic eco-system is expected to nurture a 50 billion-yuan AI-centered industry within the targeted period.

\section{CASE STUDIES}

\subsection{THE SELF-DRIVING BUSES OF SHENZHEN}

Four AI-based auto-driving buses started operational trials in December 2017 in China's southern Shenzhen city famous for its density of state-of-the-art technology companies [3]. The AI-driven buses, smaller in comparison to ordinary buses, started their trial on a $1.2 \mathrm{~km}$ trip having 3 stops in Futian's bonded zone. These buses are having a speed of ten to thirty kmph. They are equipped with smart censors, cameras, and GPS arrays, and can avoid people walking on road, other vehicles and any barriers, can also change driving-lanes and make designated stops. This project is joint-venture of the National Intelligent Transport Systems Center of Engineering and Technology and the Shenzhen Bus Group.

\subsection{THE ROBOT WHICH PASSED THE MEDICAL EXAM}

In November 2017, a robot successfully passed the written test of national medical licensing exam in China, a basic requirement for those aspiring to be doctors [4]. This development made 
DOI: https://dx.doi.org/10.26808/rs.ca.i8v2.09

International Journal of Computer Application (2250-1797)

Issue 8 Volume 2, March-April 2018

this robot the first robot globally to pass such a qualifying exam. The developer of the robot iFlytek Co Ltd, a leading Chinese AI company, reported that this robot obtained a score of 456 points, which was 96 points above the minimum qualifying marks.

The AI-based robot has features such as auto-capture and auto-analysis of patient information, and even can make basic diagnosis. The robot will help doctors for more efficient treatments in future according to the developer. Waiving off concerns, Liu Qingfeng, the chairman of the developer company said that it was not intended as replacement for doctors and instead intended to promote better cooperation between people and machines for better efficiency. The company is in the process of conducting a pilot project in the Anhui Provincial Hospital to access ways in which the AI robot may help doctors in actual medical cases. Pertinently, doctors are in acute shortage in rural areas in China. The Company hopes that AI can enable more people to access deserved medical resources. In October 2017, iFlytek said that it will start a 1.02 billion yuan (\$150 million) valued funding campaign for supporting software and hardware engineers and startups.

\subsection{BIG DATA PROMOTES CHINESE TOURISM}

Big data and its AI-based analysis, is playing a growing role in tourism in China [5]. Independent travelers share tips regularly while online and provide the tourism industry with an ever-growing treasure of data about travel destinations, hotels and restaurants. Travelers are more and more making internet-review based decisions thus making internet based reputations increasingly important. These in turn are quantifying as more big data AI-based analysis is being applied in the Chinese tourism sector.

Recently, Beijing International Studies University released a list of China's top ten highest rated scenic areas after big-data analysis was done on their online reputations, simultaneously presenting five awards in areas such as service and environment to the tourist sites. The Temple of Heaven in Beijng, earthen buildings of the Fujian province and ancient city of Pingyao of Shanxi province made it to the list.

\subsection{AN IMPORTANT PARTNERSHIP}

Baidu Inc, China's internet search giant, and Xiaomi Corp, the Chinese consumer electronics company, announced in December 2017 they had entered into a deep partnership on AI and the internet of things (IoT), for the purpose of offering a heightened user-experience in consumer electronics and also in smart devices [6]. This partnership also marks an important step in boosting the Chinese smart manufacturing industry by using advanced technology e.g. AI, IoT and big data. Bonding AI and IoT is going to be a driving force for upgradation of the manufacturing industry.

The two hi-tech partners will be exploring cooperation in various AI-based areas, such as deep learning, conversational AI, speech recognition, and machine vision. The IoT-based industry has huge potential, and AI-based technologies are in the process of supporting the development of the industry. Baidu Inc uses its DuerOS AI-based conversation system for developing the IoT industry.

\section{CONCLUSION}

AI is gathering momentum as a driving force in both the present and in the future. Though there are concerns about its effects like loss of global employment, its user and developer communities march hand in hand into the all-encompassing future. 
DOI: https://dx.doi.org/10.26808/rs.ca.i8v2.09

\section{REFERENCE}

[1] http://www.chinadaily.com.cn/a/201712/13/WS5a30c64ba3108bc8c672eaa6.html

[2] http://www.chinadaily.com.cn/a/201712/15/WS5a330a41a3108bc8c6734c64.html

[3] http://www.chinadaily.com.cn/china/2017-12/02/content_35170886.htm

[4] http://www.chinadaily.com.cn/bizchina/tech/2017-11/10/content_34362656.htm

[5] http://www.chinadaily.com.cn/a/201712/25/WS5a403ff2a31008cf16da32ea_1.html

[6] http://www.chinadaily.com.cn/business/tech/2017-11/28/content_35100891.htm 